\title{
Lightweight lignocellulosic foams for thermal insulation
}

\author{
Tia Lohtander • Reima Herrala • Päivi Laaksonen • Sami Franssila • \\ Monika Österberg (i)
}

Received: 22 September 2021/Accepted: 17 December 2021/Published online: 6 January 2022

(C) The Author(s) 2022

\begin{abstract}
Foams are mainly composed of dispersed gas trapped in a liquid or solid phase making them lightweight and thermally insulating materials. Additionally, they are applicable for large surfaces, which makes them attractive for thermal insulation. State-ofthe-art thermally insulating foams are made of synthetic polymeric materials such as polystyrene. This work focuses on generating foam from surfactants and renewable lignocellulosic materials for thermally insulating stealth material. The effect of two surfactants (sodium dodecyl sulphate (SDS) and polysorbate (T80)), two cellulosic materials (bleached pulp and nanocellulose), and lignin on the foaming and stability of foam was investigated using experimental design and response surface methodology. The
\end{abstract}

volume-optimized foams determined using experimental design were further studied with optical microscopy and infrared imaging. The results of experimental design, bubble structure of foams, and observations of their thermal conductivity showed that bleached pulp foam made using SDS as surfactant produced the highest foam volume, best stability, and good thermal insulation. Lignin did not improve the foaming or thermal insulation properties of the foam, but it was found to improve the structural stability of foam and brought natural brown color to the foam. Both wet and dry lignocellulosic foams provided thermal insulation comparable to dry polystyrene foam.

Supplementary Information The online version contains supplementary material available at https://doi.org/10.1007/ s10570-021-04385-6.

T. Lohtander · M. Österberg $(\square)$

Department of Bioproducts and Biosystems, School of Chemical Engineering, Aalto University, Espoo, Finland e-mail: monika.osterberg@aalto.fi

R. Herrala $\cdot$ S. Franssila

Department of Chemistry and Materials Science, School of Chemical Engineering, Aalto University, Espoo,

Finland

P. Laaksonen

HAMK Tech, Häme University of Applied Sciences,

Hämeenlinna, Finland 


\section{Graphical abstract}
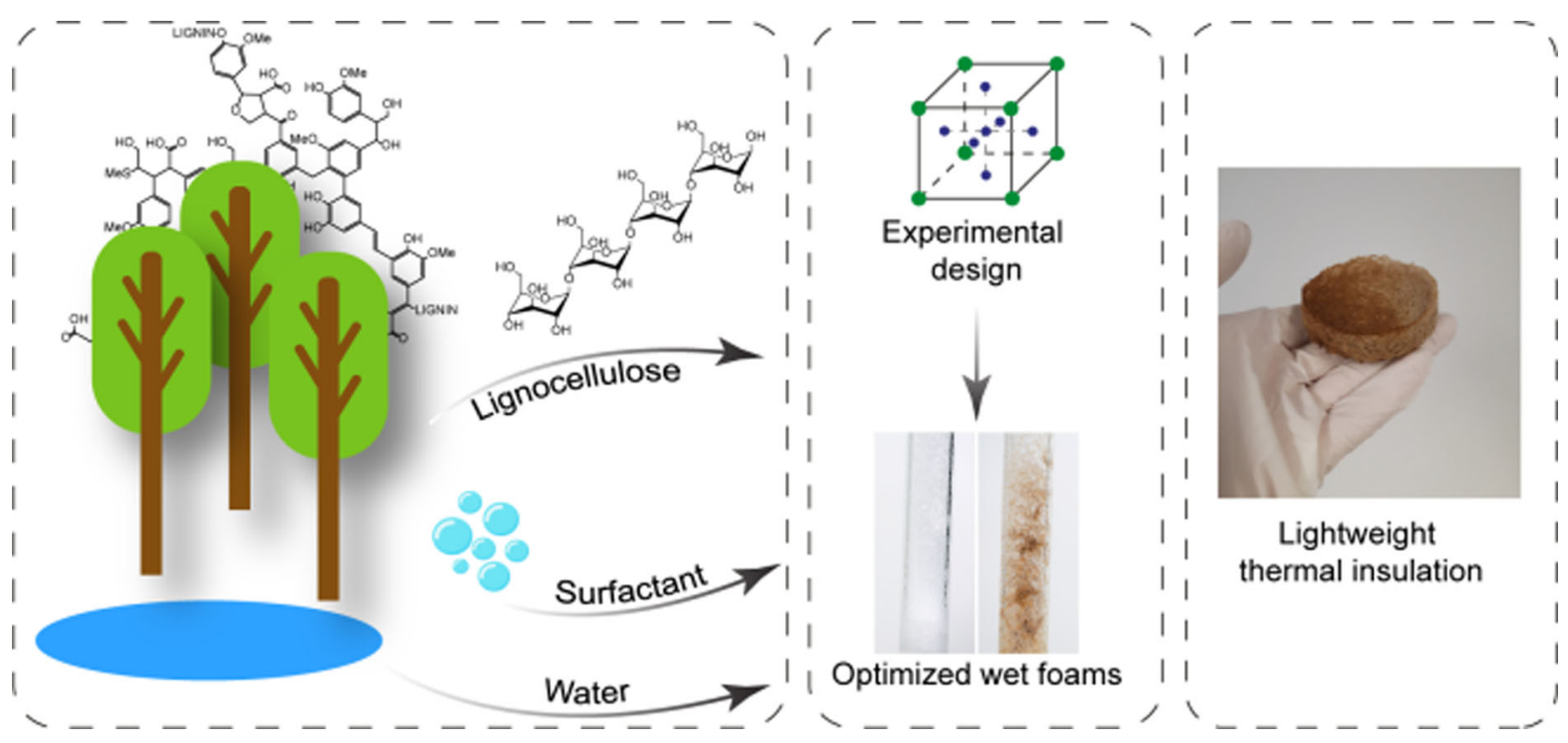

Keywords Foam $\cdot$ Cellulose $\cdot$ Nanocellulose . Lignin $\cdot$ Surfactant $\cdot$ Camouflage

\section{Introduction}

Foams are multiphase systems containing gas dispersed in a liquid or solid and they have unique mechanical, optical, electrical, and thermal properties, which can be modified by tuning the physical and chemical structure of the foam (Drenckhan and SaintJalmes 2015; Saint-Jalmes 2006). Owing to their versatile properties, low density, and large specific surface area, they are employed in many industrial applications from food and pharmaceutical industries to construction (Murray 2020; Stevenson 2012; Zhao et al. 2010). Thermal insulation is required in many applications, such as buildings, and chemical and thermal processes. Often the foams in thermal insulation applications are polymeric solid foam panels, for instance, polyurethane or polystyrene, which are formed from liquid foams containing precursors that polymerize and solidify the foam after foam generation (Langevin 2017; Rio et al. 2014). However, the environmental awareness and EU visions together with United Nations Sustainable Development Goals are pushing industries toward more sustainable and environmentally friendly technologies (European Commission 2018; United Nations 2015). From this perspective, replacing petroleum-based foams with renewable raw materials is a topical issue.

In addition to insulation in buildings, thermally insulating materials are also applied in stealth technology. Camouflage materials, inspired by nature, are utilized to create low observability for defense applications like vehicles and armor (Deepti et al. 2018). Camouflage nets, paints, smoke, and trees are conventional techniques employed on-site to cover armaments. The visual stealth, however, is no longer enough, since the widely applied hyperspectral detectors observe signals from visible to infrared wavelengths (400-1000 nm) (Deepti et al. 2018). Recently, research in infrared stealth technology has focused on high technology solutions, such as radar absorbing materials and photonic structures, which are effective materials but limited to rather small areas and usually very expensive (Kim et al. 2017; Wang et al. 2014). In contrast, foams are relatively cheap, lightweight and could be scalable to cover large surface areas.

Foam can be generated with almost any liquid by introducing gas, however, without stabilizing components they collapse within minutes. Surfactants are adsorbed at the gas-liquid interface, where they reduce the surface tension, provide repulsion between bubbles and thus improve the stability of liquid foam 
(Wang et al. 2016). The shape and size of gas bubbles and the liquid fraction determine whether the foam is dry, wet, or a bubbly liquid (which actually does not fulfill the definition of foam) (Drenckhan and Hutzler 2015; Lappalainen and Lehmonen 2012).

Foam formation and foam stability are complicated processes influenced by multiple mechanisms taking place simultaneously. The foaming of a surfactant solution can be performed with mechanical stirring, gas injection, or by chemical reactions, and typically the bubble size ranges from a few hundred microns even to one centimeter depending on the applied foaming technique (Drenckhan and Saint-Jalmes 2015). The achieved foam volume is mainly governed by the foamability of the surfactant and surfactant concentration, but other process parameters should also be taken into consideration. For instance, an increase in rotational speed decreases the bubble size, increases the foam volume, and decreases the density of foam during mechanical stirring (Samaras et al. 2014; Wu et al. 2012). Surfactants are essential for the foaming process because they decrease the surface tension allowing more foam to be formed. The chemical structure, and thus the tendency to adsorb at the air-water interface and critical micelle concentration affect the performance of the surfactant (Amaral et al. 2008; Wang et al. 2016). The foamability of surfactant solutions is typically characterized qualitatively by observing the volume or height of foam column in graduated cylinders (Bikerman 1938) with various geometries and the comparison of foamability between studies is difficult as the test designs and conditions vary.

The liquid foams are thermodynamically unstable systems, and without stabilizing agents, they quickly age and collapse after formation. The ageing of foam occurs via three mechanisms: drainage, coalescence, and coarsening (Drenckhan and SaintJalmes 2015; Saint-Jalmes 2006). Due to the gravity, the liquid trapped in foams drains quickly. Over time, the foams become coarser as the gas flows from smaller bubbles to larger ones (coarsening), and eventually the films between bubbles rupture (coalescence). The increasing bubble size accelerates drainage as the thickness of liquid channels increase (Lappalainen and Lehmonen 2012). Even with a surfactant, the coarsening of foam is difficult to prevent (Murray and Ettelaie 2004).
In addition to employing surfactants, there are mainly two stabilization methods to slow down the drainage-driven ageing of foam. The first method is to increase the viscosity of the liquid phase, which slows down the flow of liquid from foam and thus restrains drainage. Second, adding particles or fibers as stabilizing additives, (i.e. Pickering agents) can delay ageing as well since the particles trapped in the film between bubbles prevent the liquid from flowing out of the foam (Lam et al. 2014; Murray and Ettelaie 2004). In some cases, the added particles also increase the viscosity of the foam, which also restrains drainage and ageing (Murray and Ettelaie 2004).

Cellulose and lignin, often referred to as lignocellulosic materials, are abundant, renewable, and lowcost materials obtained from plant biomass from the forest industry. They can improve mechanical properties and the stability of foams (Arevalo-Gallegos et al. 2017). Previously in foam research, lignin and cellulose nanofibrils have been studied for the stabilization of wet foams ( $\mathrm{Li}$ et al. 2016a, b; Xiang et al. 2019). In addition to their stabilization effect, nanocellulose containing dry foams have been shown to have low thermal conductivity making them an attractive alternative for thermally insulating materials (Farooq et al. 2018a; Jiménez-Saelices et al. 2017; Sakai et al. 2016). The foams presented here were intended to be used as easily and rapidly applicable, temporary, and eco-friendly stealth material in a forest environment. To the best of our knowledge, the combination of liquid foams and lignocellulose has not been utilized for thermal and optical stealth applications previously. Lignocellulosic dry foams have been studied for various other applications, such as adsorption (Ferreira et al. 2020), filtration (Nemoto et al. 2015), sound insulation (Nechita and Nâstac 2017), and packaging (Ago et al. 2016). Common for these studies is that the foams were utilized as dry while here also the wet foams were used.

Herein, the effect of two surfactants (SDS, Tween80), two cellulosic materials (bleached pulp, nanocellulose), and lignin on foaming and foam stability were studied using response surface methodology. This experimental design allowed us to explore the foaming process with a small number of experiments despite many variables. The experimental design aimed to find optimal concentration for creating maximum foam volume with a simple foaming process. Based on the empirical data obtained from 
experiments, a statistically satisfactory model and a response surface were created that was used to predict the foam volume within the same experimental conditions and factor range. The optimum concentration ranges for the two surfactants, two cellulosic materials, and lignin were obtained from the response surfaces. In addition to foaming, the stability of foam was studied with experimental design. The thermal insulation capabilities of various wet and dry foams were analyzed by imaging foams with an infrared camera. The thermal insulation of optimized foams was tested along with additional screening tests with varying foam thickness, SDS, lignin and surfactant concentrations.

\section{Experimental}

\section{Materials}

Bleached pulp having $12.7 \%$ dry weight and 2.9 weight-\% dispersion of cellulose nanofibrils (CNFs) were prepared from never-dried, bleached Kraft birch pulp with a high-pressure microfluidizer (Model M-110Y, Microfluidics, USA). The fluidization method and properties of the CNFs have been described in detail by Farooq et al. (Farooq et al. 2018b). Cellulose nanofibrils typically have a diameter in the nanometer range and a length of several microns, and bleached pulp has lateral dimensions in the micron range and length in the millimeter scale (Klemm et al. 2005, 2011). Kraft lignin was purchased from UPM (UPM BioPiva 100). Sodium dodecyl sulphate (SDS, Sigma Aldrich) and polysorbate (Tween 80, T80, Sigma Aldrich) were used as surfactants in foam preparation. Deionized water was used in all samples.

\section{Foam generation}

Lignocellulosics (pulp or CNF and lignin), a surfactant, and water (in total $12.5 \mathrm{~mL}$ ) were mixed in varying ratios according to the experimental design matrix in Fig. 1, and the foam was generated by mechanical stirring using an Ultra-Turrax homogenizer (IKA T18, IKA Works GmbH \& Co. KG, Germany) for $2 \mathrm{~min}$. Foams were poured carefully into graduated cylinders immediately after foaming and were recorded on video for foam volume changes and drainage analysis. The foam volume and drainage over time were assessed from freeze-frames using image processing software (imageJ, National Institutes of Health, USA).

\section{Experimental design}

Experimental design and response surface methodology were employed to optimize the concentrations of foam components and to evaluate the effect of components on the foaming result. The optimization aimed at creating maximum volume of foam. A central composite design with three factors and three replicated center points was applied. The concentrations of components, including cellulosic material, surfactant, and lignin, were varied at three levels from -1 to 0 and +1 , resulting in 17 experiments that were all repeated twice. Since two different cellulosic materials and surfactants were used, four separate experimental designs with similar concentration ranges were conducted (Pulp + SDS, CNF + SDS, Pulp + T80, $\mathrm{CNF}+\mathrm{T} 80$ ). A mathematical model and response surface for foam volume and drainage at $5 \mathrm{~min}$ and $2 \mathrm{~h}$ were created based on the collected empirical data. The experimental design and statistical analysis were carried out using MODDE 8.0 (Umetrics, Sweden) software. Figure 1 shows the experimental design and central composite design matrix. The concentration of cellulosics varied from $1.265 \mathrm{~g} / \mathrm{L}$ to $12.65 \mathrm{~g} / \mathrm{L}$, surfactant from $2 \mathrm{~g} / \mathrm{L}$ to $30 \mathrm{~g} / \mathrm{L}$, and lignin from 0 to $160 \mathrm{~g} / \mathrm{L}$. The applied concentration ranges were selected based on preliminary screening experiments carried out prior to the experimental design. The adequacy of the model was determined by evaluating the coefficient of determination $\left(\mathrm{R}^{2}\right)$, the lack of fit, and the p-values (ANOVA) with a confidence level of 95\%. To evaluate the obtained models, the optimized factors (i.e. the concentrations of components) were tested experimentally, and the predicted foam volume values were compared to the corresponding actual experimental values. From each of the four tests, two experiments were selected; aiming to maximize foam volume with and without lignin. According to the selected criteria, the software calculated the optimum concentrations for each factor based on the prediction model. The relative deviation between predicted and experimental values of foam volume was calculated with the following equation 


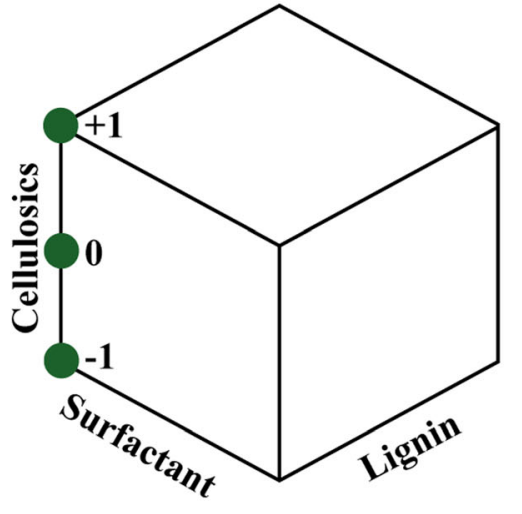

\begin{tabular}{|c|c|c|c|}
\hline Factor & Cellulosics (g/L) & Surfactant (g/L) & Lignin (g/L) \\
\hline-1 & 1.265 & 2 & 0 \\
\hline 0 & 6.958 & 16 & 80 \\
\hline+1 & 12.65 & 30 & 160 \\
\hline
\end{tabular}

\begin{tabular}{|c|c|c|c|}
\hline Run no & Cellulosics (g/L) & Surfactant (g/L) & Lignin (g/L) \\
\hline 1 & 1.265 & 2 & 0 \\
\hline 2 & 12.65 & 2 & 0 \\
\hline 3 & 1.265 & 30 & 0 \\
\hline 4 & 12.65 & 30 & 0 \\
\hline 5 & 1.265 & 2 & 160 \\
\hline 6 & 12.65 & 2 & 160 \\
\hline 7 & 1.265 & 30 & 160 \\
\hline 8 & 12.65 & 30 & 160 \\
\hline 9 & 1.265 & 16 & 80 \\
\hline 10 & 12.65 & 16 & 80 \\
\hline 11 & 6.958 & 2 & 80 \\
\hline 12 & 6.958 & 30 & 80 \\
\hline 13 & 6.958 & 16 & 0 \\
\hline 14 & 6.958 & 16 & 160 \\
\hline 15 & 6.958 & 16 & 80 \\
\hline 16 & 6.958 & 16 & 80 \\
\hline 17 & 6.958 & 16 & 80 \\
\hline
\end{tabular}

Fig. 1 The central composite design visualized and experimental matrix showing the concentrations for factors

Relative deviation $R D \%=\frac{y_{\text {exp. }}-y_{\text {pred }}}{y_{\text {exp. }}} \times 100$

where $y_{\text {exp. }}$ is experimental foam volume and $y_{\text {pred. }}$ is predicted foam volume based on the model.

\section{Characterization of foams}

Bubble shapes and sizes were analyzed with an optical microscope (DM750, Leica, Germany) using $10 \times$ magnification. In addition to visual observations, the liquid fraction $\phi$ of foams was used for characterization. The liquid fraction $\phi$ is defined as the volume of liquid divided by the total volume of foam, and foams are categorized as dry foam $(\phi<0.05)$, wet foam $(\phi>0.15)$ and bubbly liquid $(\phi>0.36)$ (Drenckhan and Hutzler 2015). The total volume of water in all samples was $12.5 \mathrm{~mL}$, and the volumes of foam phases were obtained from the same videos used for foam stability measurements.
Thermal insulation

The foams prepared using bleached pulp as the cellulosic component were selected for thermal insulation experiments. The pulp foams for thermal insulation studies were generated as described earlier in the foam generation section. Thermal conductivity and diffusivity of foams were studied by placing the foams on a hot plate (IKA C-MAG HS10 digital) and monitoring the top surface temperature with an infrared camera (FLIR One Pro for Android, spatial resolution $160 * 120$ pixels, thermal sensitivity $150 \mathrm{mK}$ MRDT). A copper plate $(155 \mathrm{~mm} \times 155 \mathrm{~mm} \times 1$ $\mathrm{mm}$ ) was used on the hot plate to ensure thermal uniformity. Foams were confined in plastic cylinders (PEX, crosslinked polyethylene), $5.9 \mathrm{~cm}$ in diameter, and resulting in a foam height of 1,2 , and $4 \mathrm{~cm}$. As a reference, a $2 \mathrm{~cm}$ thick polystyrene foam was used. 


\section{Results and Discussion}

\section{Optimization of foaming}

The objective of this work was to investigate the influence of surfactant choice, cellulosic material, and the presence of lignin on the generated foam volume using an experimental design. Obtaining maximum volume of foam was essential for the application as stealth material since in the field conditions it is preferred to create maximum foam volume at once. The applied concentration ranges were obtained from preliminary screening experiments carried out prior to the experimental design. The response surfaces showed that the applied surfactant is the major factor for achieving the highest foam volume (Fig. 2). The corresponding numerical experimental data is presented in Figs. S2-S5 in SI. SDS produced twice as much foam as T80, which is due to the better foaming capacity of SDS using the foaming technique applied herein (SI Fig. S1). The critical micelle formation, which is one of the most important parameters of surfactants, has a significant role in foaming too. The optimal foaming properties are found when the surfactant concentration is above the critical micelle concentration (CMC) (Xu et al. 2009). The concentrations of both T80 and SDS were above the CMC limit in all experiments $\left(\mathrm{CMC}_{\mathrm{SDS}} 8 \mathrm{mM}, \mathrm{CMC}_{\mathrm{T} 80}\right.$ $0.012 \mathrm{mM}$ ) (Casero et al. 1997; Chou et al. 2005). These results are consistent with previous research where SDS has been found to produce more foam than T80 (Amaral et al. 2008), although these types of systems have not been previously studied. The volume of generated foam was directly proportional to the surfactant concentration, that is, the higher the concentration of SDS or T80, the more foam was formed. When using SDS as a surfactant, a medium to high concentration of cellulosic material yielded the largest foam volumes. The cellulose concentration range that produced the highest amount of foam was rather wide for bleached pulp compared to $\mathrm{CNF}$, which had a narrower optimal cellulose concentration range (Fig. 2a, b). Nevertheless, the maximum amount of foam was quite similar for pulp and CNF when SDS was used as a surfactant.

The influence of cellulose concentration on foam volume differed significantly compared to SDS when T80 was used as a surfactant. With T80, the highest foam volumes were found using a low concentration of cellulosics, either pulp or CNF. However, the foam volume was much lower, only half of the volume obtained with SDS at optimal conditions (Fig. 2c, d). The CNF + T80 seemed to result in a more viscous bubbly gel than foam, but according to the liquid fraction $(\phi)$, the solute can still be classified as a wet foam (Table 1).

Nanocellulose (CNF) is known to create viscous gels even at low concentrations in water, and a larger increase in viscosity is known to reduce the gas content of the foam and thus the volume of generated foam (Drenckhan and Saint-Jalmes 2015; Klemm et al. 2011). However, to some extent, high viscosity of the aqueous phase is advantageous since it stabilizes the foam (Xiang et al. 2019). The viscosity of the foams was not measured here but it can be assumed that CNF has the same effect on viscosity regardless of the used surfactants. Since CNF + SDS, even with a relatively high $\mathrm{CNF}$ concentration, formed a large foam volume the low foaming of $\mathrm{CNF}+\mathrm{T} 80$ was most likely due to the poorer foaming performance of T80 compared to SDS within these experimental conditions and not due to high viscosity. It is possible that T80 could have reached a similar foaming capacity as SDS if more energy or longer mixing time would have been applied. However, it is not desirable to increase the used energy from economical or ecological points of view. In addition to the tendency to adsorb at the air-water interface, the differences in chemical structures of the surfactants affect the interaction with the lignocellulosic components in the suspension. It can be assumed that T80, as a nonionic surfactant, could have a higher tendency than anionic SDS to also adsorb onto the anionic lignocellulosics. This would leave less surfactant for foam formation. Nonionic surfactants have been shown to exhibit better adsorption on hydrophilic cellulose surfaces than anionic surfactants, although the adsorption of the latter one can be improved with electrolytes (Paria et al. 2005). A strong interaction between surfactants and polymers has been shown to lead to low foamability (Petkova et al. 2012). In contrast, Xiang et al (2019) demonstrated that the foamability of SDS was similar in the presence and absence of CNF when the SDS concentration was above the critical micelle concentration. This indicates, no or only weak interactions between SDS and CNF.

Lignin was assumed to influence foamability due to its amphiphilic properties arising from a combination 
(A)
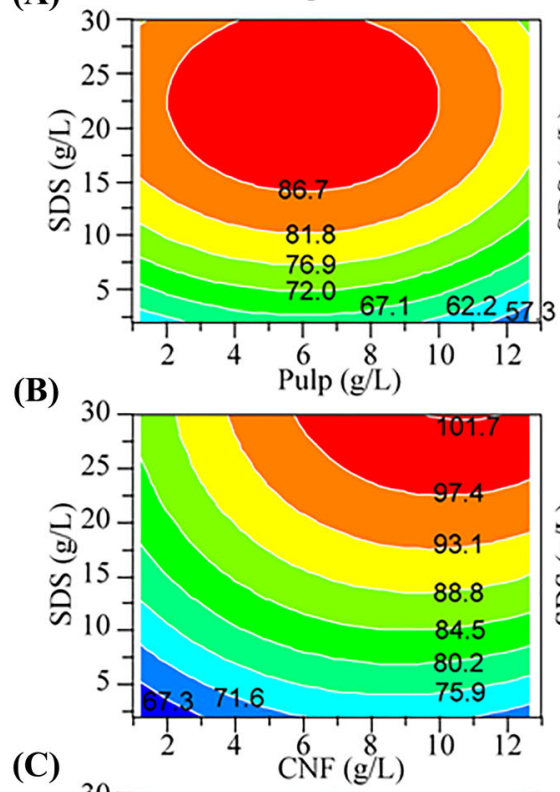

(C)

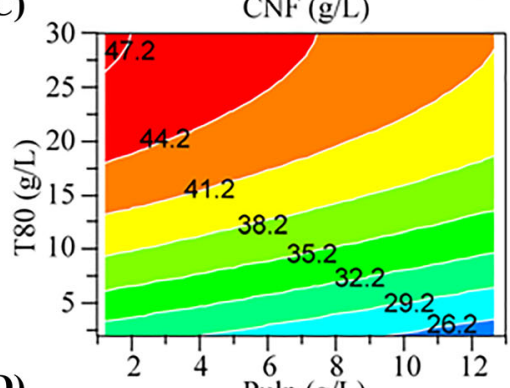

(D)

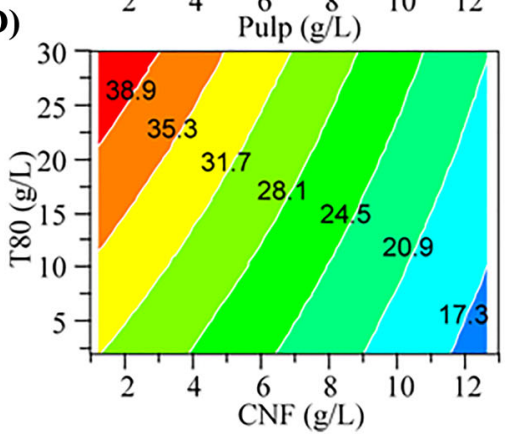

Fig. 2 Response surfaces of predicted foam volume (mL) as a function of surfactant and cellulosic materials concentrations, with three lignin concentrations. (a) Pulp + SDS (b) CNF + SDS (c) Pulp $+\mathrm{T} 80$ (d) $\mathrm{CNF}+\mathrm{T} 80$. The factor ranges

of a hydrophobic backbone and hydrophilic functional groups ( $\mathrm{Li}$ et al. 2016a). Surprisingly, the lignin concentration appeared to have only a small or no effect on the foaming, and no clear trend could be observed. This is in agreement with previous findings that show lignin often requires chemical modification to work as a surfactant (Alwadani and Fatehi 2018).
Lignin $80 \mathrm{~g} / \mathrm{L}$
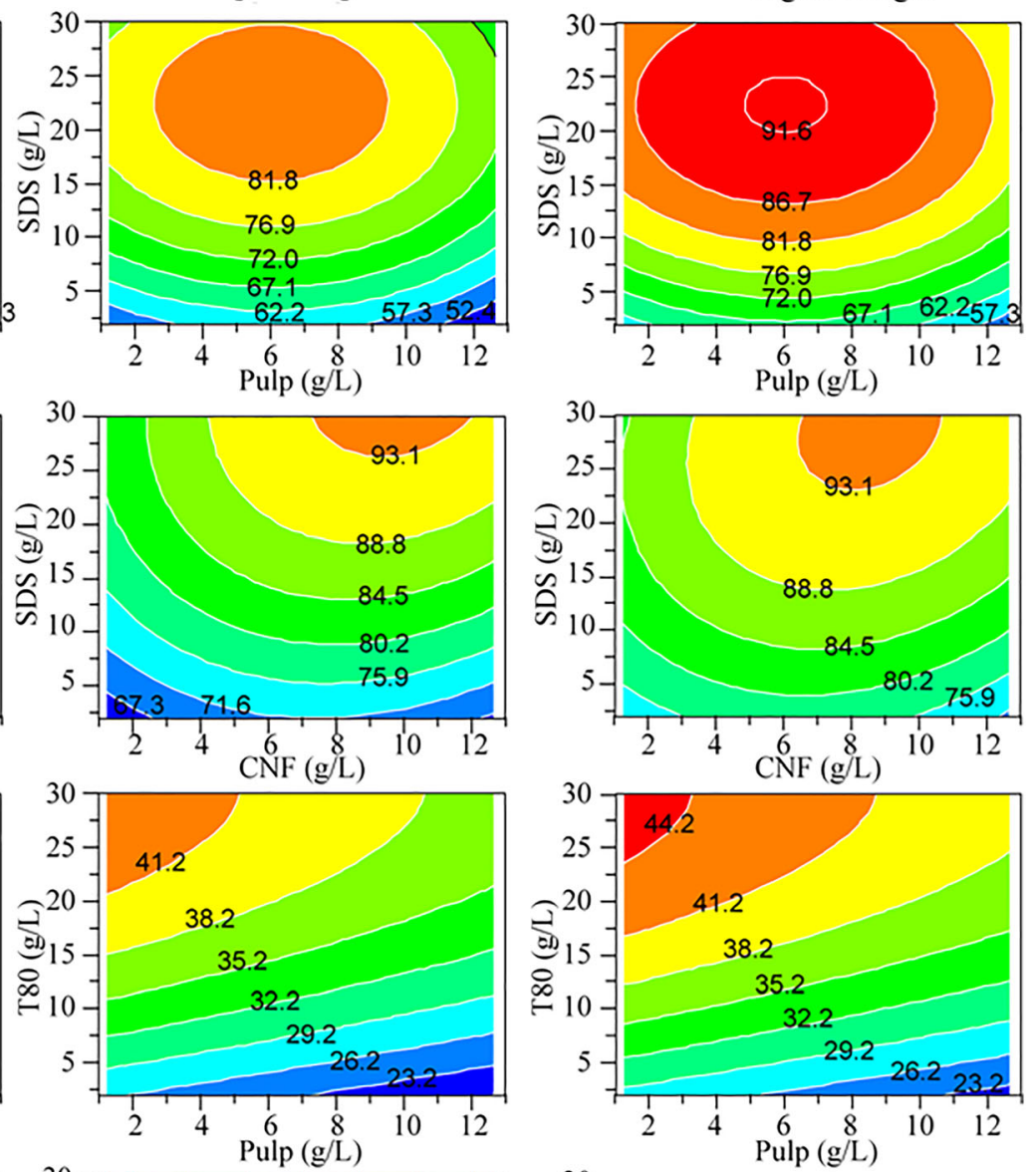

Pulp $(\mathrm{g} / \mathrm{L})$
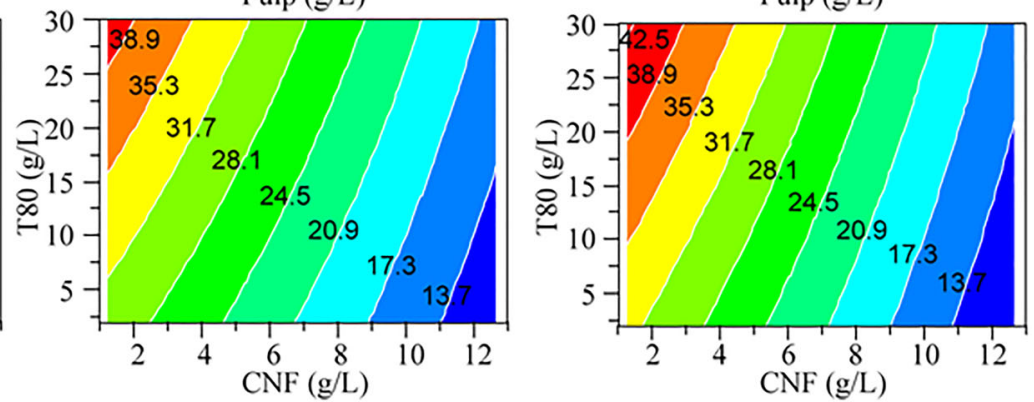

generating the highest foam volume are marked with red and the ones generating the lowest foam volume are marked with blue. The given values indicate the lower/upper limit of each range

The predictions from the experimental design were validated by experimentally testing the systems with the optimum ratio of components (Table 1). The optimization aimed to create the maximum amount of foam with and without lignin. Although the statistical validation of models indicated that the prediction models have some uncertainty (SI Fig. S2-S5), the 
Table 1 Experimental validation of optimized foam volume model predictions. $V_{\text {pred. }}$ is the predicted foam volume and $V_{\text {exp. }}$ is the experimental volume of samples
${ }^{\text {a }}$ Relative deviation (RD) describes the difference between predicted and experimental foam volumes, ${ }^{\mathrm{b}}$ Liquid fraction $\phi(\%)$ is the volume of liquid divided by the total volume of foam

\begin{tabular}{|c|c|c|c|c|c|c|c|}
\hline & & & & $V_{\text {pred. }}(\mathrm{mL})$ & $V_{\text {exp. }}(\mathrm{mL})$ & $\mathrm{RD}(\%)^{\mathrm{a}}$ & $\phi(\%)^{\mathrm{b}}$ \\
\hline \multicolumn{8}{|c|}{ Test 1: Pulp + SDS } \\
\hline & Pulp (mg) & SDS (mg) & Lignin (mg) & & & & \\
\hline 1 & 6.1 & 22.4 & 160.0 & 91.6 & 91 & 1.1 & 13.16 \\
\hline 2 & 7.0 & 21.6 & 0 & 86.7 & 80 & 1.2 & 14.87 \\
\hline \multicolumn{8}{|c|}{ Test 2: Pulp + T80 } \\
\hline & Pulp (mg) & $\mathrm{T} 80$ (mg) & Lignin (mg) & & & & \\
\hline 1 & 1.265 & 29.6 & 160.0 & 45.3 & 45 & 2.2 & 27.54 \\
\hline 2 & 1.265 & 30.0 & 0 & 47.6 & 47 & 2.1 & 26.36 \\
\hline \multicolumn{8}{|c|}{ Test 3: CNF + SDS } \\
\hline & CNF (mg) & SDS (mg) & Lignin (mg) & & & & \\
\hline 1 & 8.5 & 29.1 & 160.0 & 93.9 & 91 & 1.1 & 9.81 \\
\hline 2 & 10.4 & 30.0 & 0 & 101.9 & 95 & 1.0 & 8.59 \\
\hline \multicolumn{8}{|c|}{ Test 4: CNF + T80 } \\
\hline & $\mathrm{CNF}(\mathrm{mg})$ & T80 (mg) & Lignin (mg) & & & & \\
\hline 1 & 1.265 & 30.0 & 160.0 & 42.9 & 44 & 2.3 & 27.31 \\
\hline 2 & 1.265 & 30.0 & 0 & 42.2 & 45 & 2.4 & 26.70 \\
\hline
\end{tabular}

relative deviation between predicted and experimental volume was quite small, indicating that the models were repeatable and provided enough predictiveness.

\section{Stability of foams}

After foam generation, the liquid starts to drain from the foam phase due to gravity. A thinning of bubble films lead to their rupture and eventually to coarsening of the foam (Wang et al. 2016). In this study, the stability of foams was characterized in terms of the amount of drained liquid measured 5 min and $2 \mathrm{~h}$ after foam generation. The liquid fraction and bubble size are both crucial parameters for foam stability (SaintJalmes 2006). Due to the simplicity and better suitability for the experimental design method, the stability was determined through the amount of liquid fraction due to drainage. As one intended use of the foam was as temporary stealth in forest environment, the long-term stability of wet foams was not explored.

The main factor influencing the drainage after 5 min was the used cellulosic material (Fig. 3). CNF containing foams had significantly less drainage $(0.5-1 \mathrm{~mL}$ at best) than pulp foams $(2.7-7 \mathrm{~mL}$ at best). The drained liquid was inversely proportional to the CNF concentration. CNF can form a gel even at low concentrations, leading to an increase in the viscosity of the CNF suspension and the viscosity increases along with CNF concentration (Mendoza et al. 2018). Therefore, it can be assumed that increasing the CNF concentration increases the viscosity of the aqueous phase leading to stabilization of the foam, which is an important factor in preventing and slowing down drainage (Murray and Ettelaie 2004). The stabilization capability is also related to the water-holding capacity of CNF arising from hydrogen bonding between water and CNF. It is also possible that $\mathrm{CNF}$ act as a Pickering stabilizing agent assembling at the air-water interface (Lam et al. 2014).

Similar behavior was seen with pulp foams, that is, the more pulp in the foam, the more stable the foam was (Fig. 3a, c). Even though the foamability did not improve with lignin, the foam stability was found to be enhanced by adding lignin to it. This finding is in agreement with previous work demonstrating that lignin-containing foams have improved stability compared to foams without lignin additive ( $\mathrm{Li}$ et al. 2016b). In three out of four experiments, the lignin concentration improved the foam stability (Fig. 3a, b, and d). Only in the case of pulp and T80, the effect of lignin was inverse, and the smallest drainage and thus best stability was obtained without lignin (Fig. 3c). This finding was unexpected since lignin was assumed to work as Pickering stabilizing particle. The observation could be due to the higher adsorbing tendency of nonionic T80 to anionic lignin, leading to the lower stability of the foam in this case. 
(A)
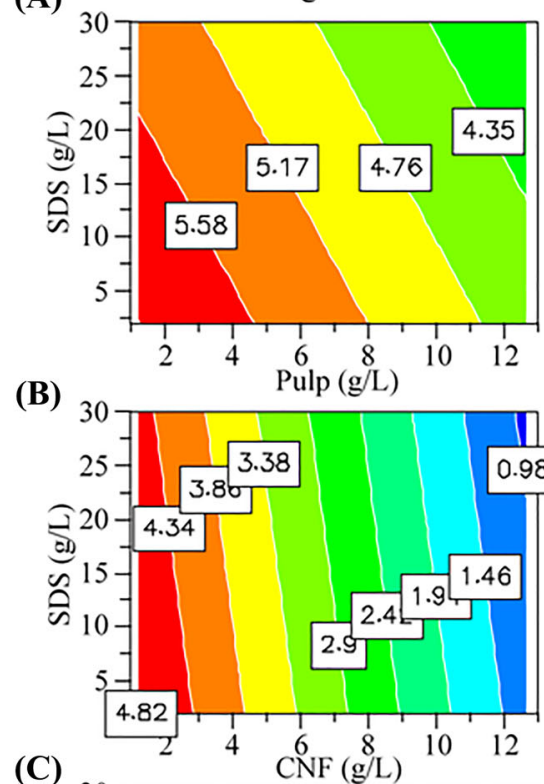

(C)
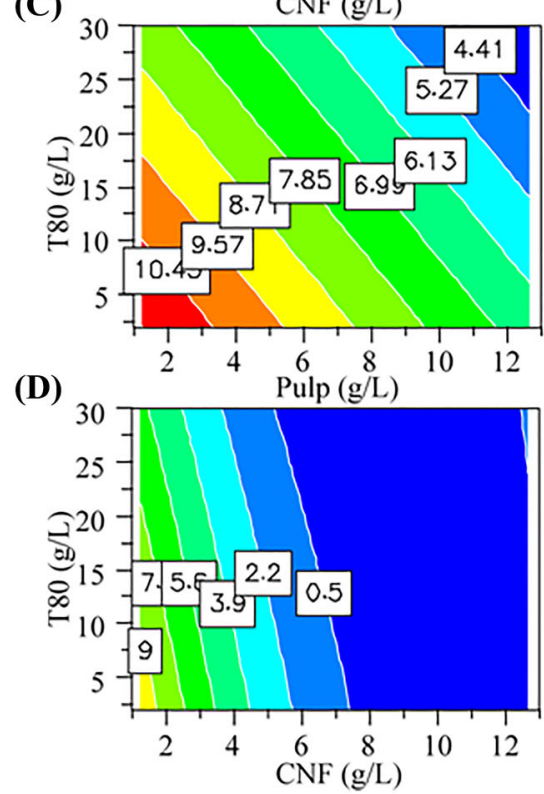

Lignin $80 \mathrm{~g} / \mathrm{L}$
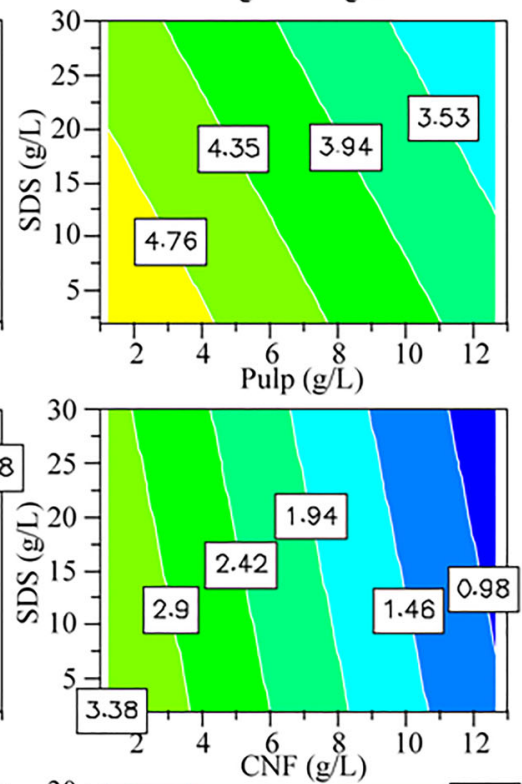
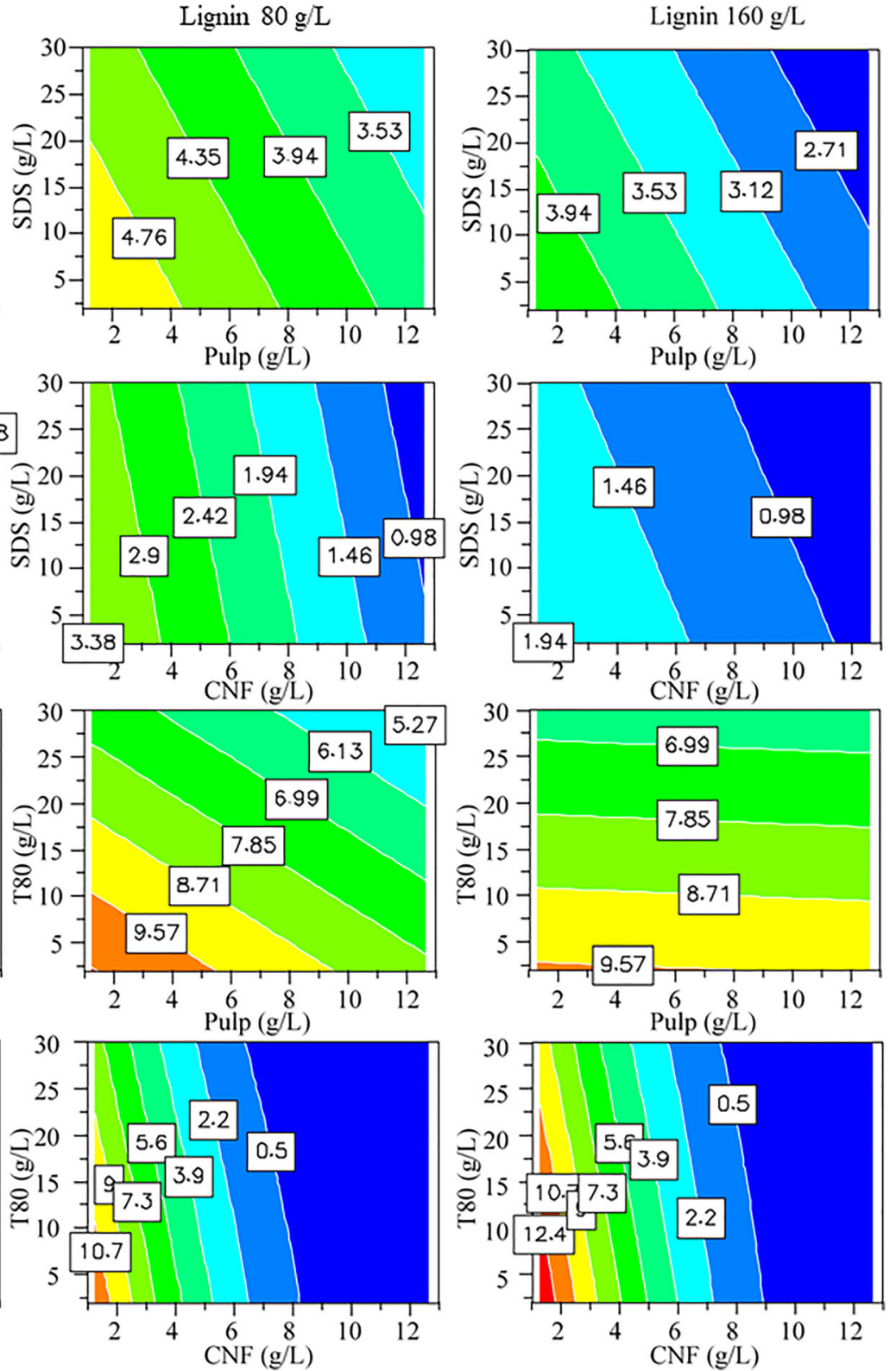

Fig. 3 Response surfaces of the predicted drainage (mL) $5 \mathrm{~min}$ after foam generation. (a) Pulp foam with SDS, (b) CNF foam with SDS, (c) Pulp foam with T80, and (d) CNF foam with T80.

Two hours after foaming, the ageing of foams had proceeded, and the drainage had increased in all foam samples (Fig. 4). The trends were similar to those in the initial drainage at $5 \mathrm{~min}$, but the differences between foams containing pulp and CNF were smaller, showing that the drainage for CNF containing foams was slower than for pulp containing foam, but eventually, they reached a rather similar liquid
The factor ranges generating the lowest drainage are marked with blue and the highest drainage marked with red. The given values indicate the lower/upper limit of each range

fraction. The positive effect of lignin observed $5 \mathrm{~min}$ after foam formation (Fig. 3a, b, and d) were not visible after $2 \mathrm{~h}$ of drainage (Fig. $4 \mathrm{a}, \mathrm{b}$, and d). The drainage for CNF + T80 with a high CNF concentration in Fig. 4d was extremely low compared to the other foams, but the foam was initially more like a viscous gel with bubbles than purely a foam, so this result may mostly reflect the stability of CNF 
(A)

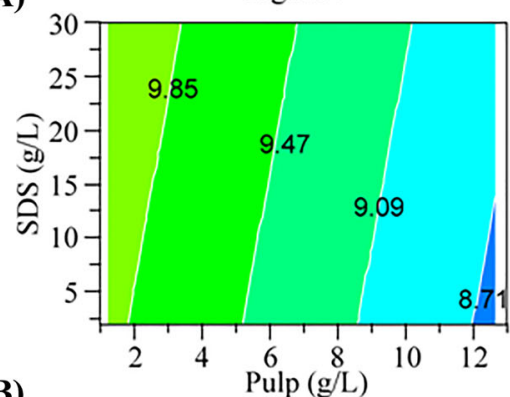

(B)
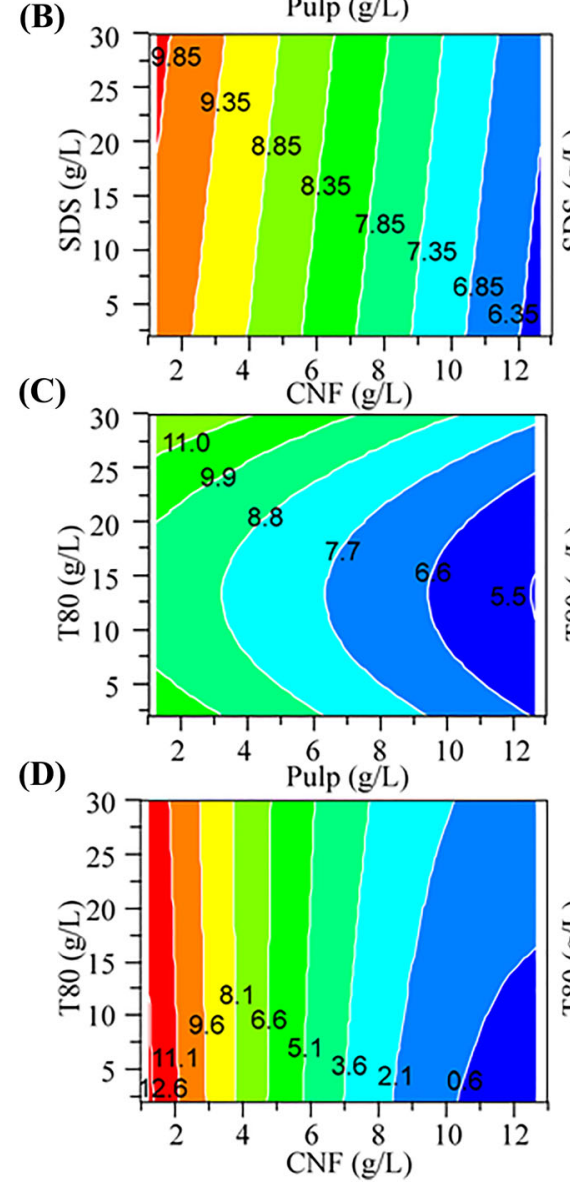

Lignin $80 \mathrm{~g} / \mathrm{L}$
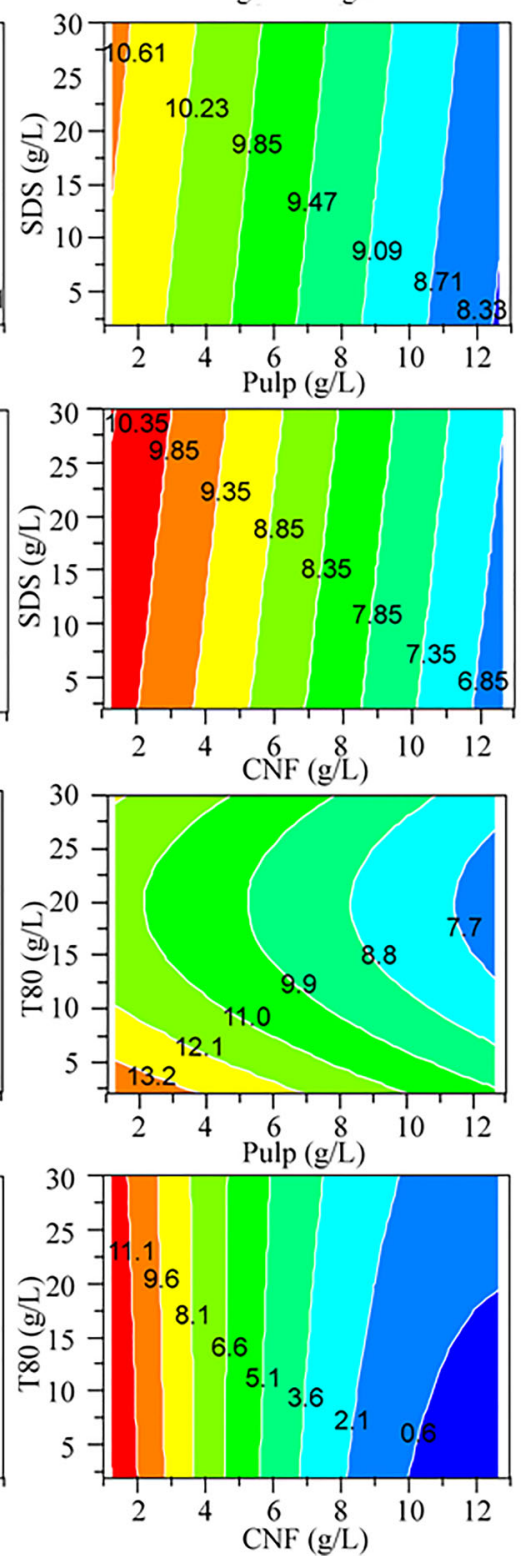

Lignin $160 \mathrm{~g} / \mathrm{L}$
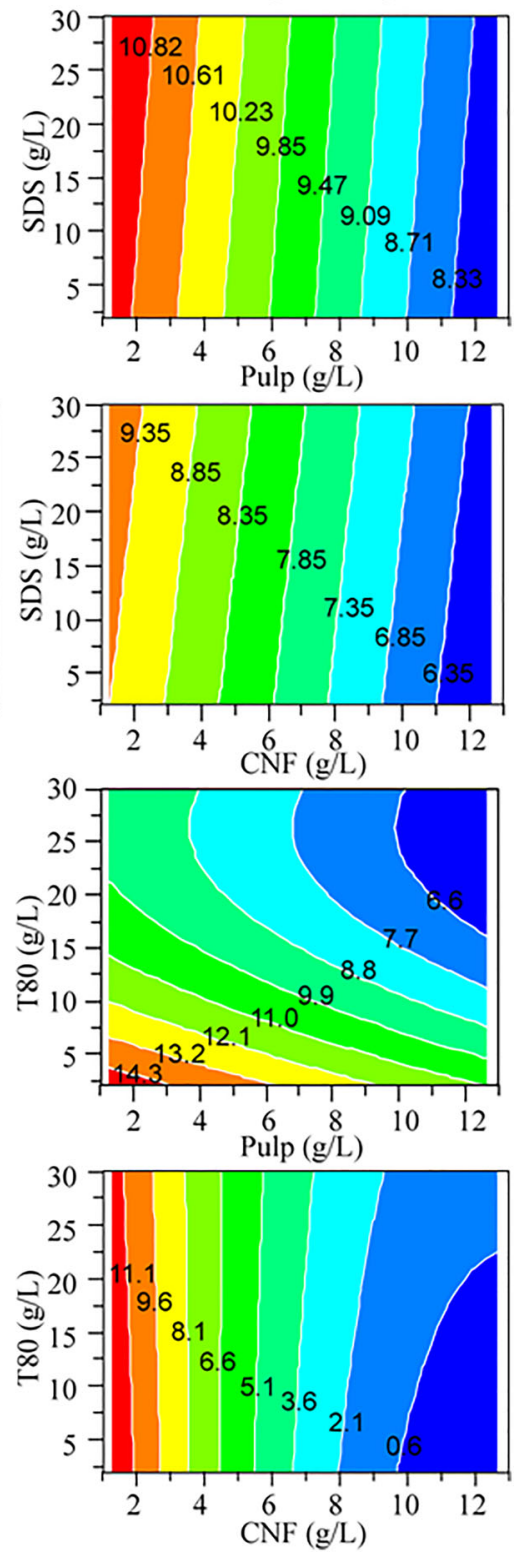

Fig. 4 The drainage (mL) $2 \mathrm{~h}$ after foam generation. (a) Pulp foam with SDS, (b) CNF foam with SDS, (c) Pulp foam with T80, and (d) CNF foam with T80. The factor ranges generating

hydrogels and not so much the foaming properties of T80. CNF in aqueous suspensions forms gels even at relatively low concentrations (Klemm et al. 2011). This characteristic of CNF has been shown to effectively slow down the ageing of wet foam (Xiang et al. 2019). the lowest drainage are marked with blue and the highest drainage marked with red. The given values indicate the lower/ upper limit of each range

Visual characterization of the foam structure

The optimized foams (Table 1) were imaged with an optical microscope to visually assess the evolution of foams because the analysis of drained liquid did not describe the coarsening process taking place in the foam phase. Visual characterization aimed to observe the differences in size and shapes of bubbles between 
optimized foams and how they were related to the foaming and stability properties obtained in experiments. The foams were imaged immediately after foam generation, during destabilization (10 $\mathrm{min})$, and after drying in ambient conditions overnight (Fig. 5). Based on their liquid fraction, all foams were categorized as wet foams (Table 1), and the bubble size of the foams was submillimetric, which is typical for foams generated with mechanical stirring (Drenckhan and Saint-Jalmes 2015). Bubbles in SDS foams were polyhedron shaped and the bubbles were separated by thin films. With T80, the bubbles were spherical and two to three-fold smaller than with SDS, and the bubbles did not have contact with neighboring bubbles due to liquid between the bubbles. These observations
(A)
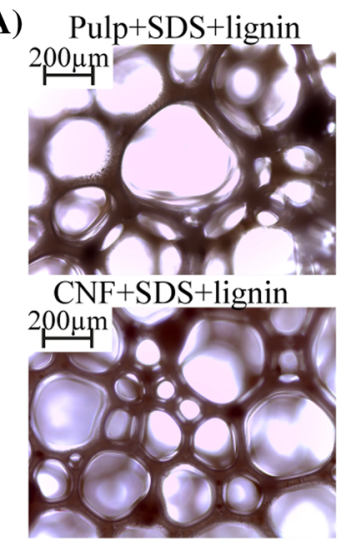

(B)

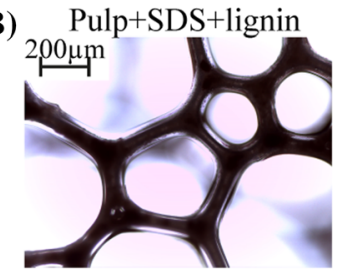

$\mathrm{CNF}+\mathrm{SDS}+$ lignin

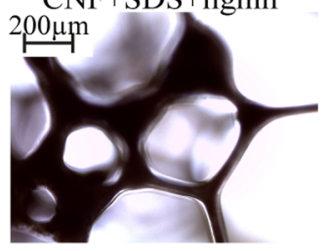

(C)

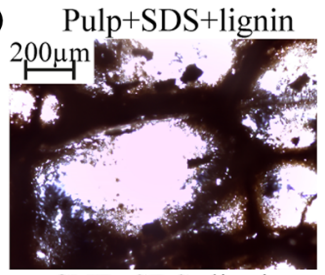

$\mathrm{CNF}+\mathrm{SDS}+$ lignin

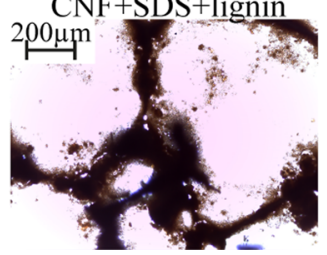

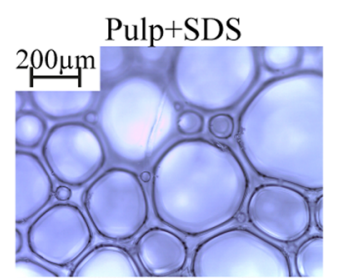
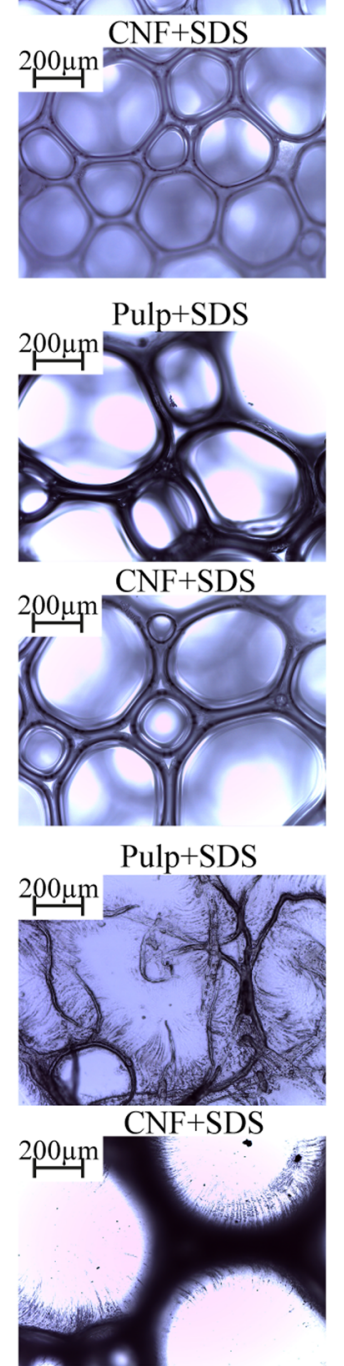
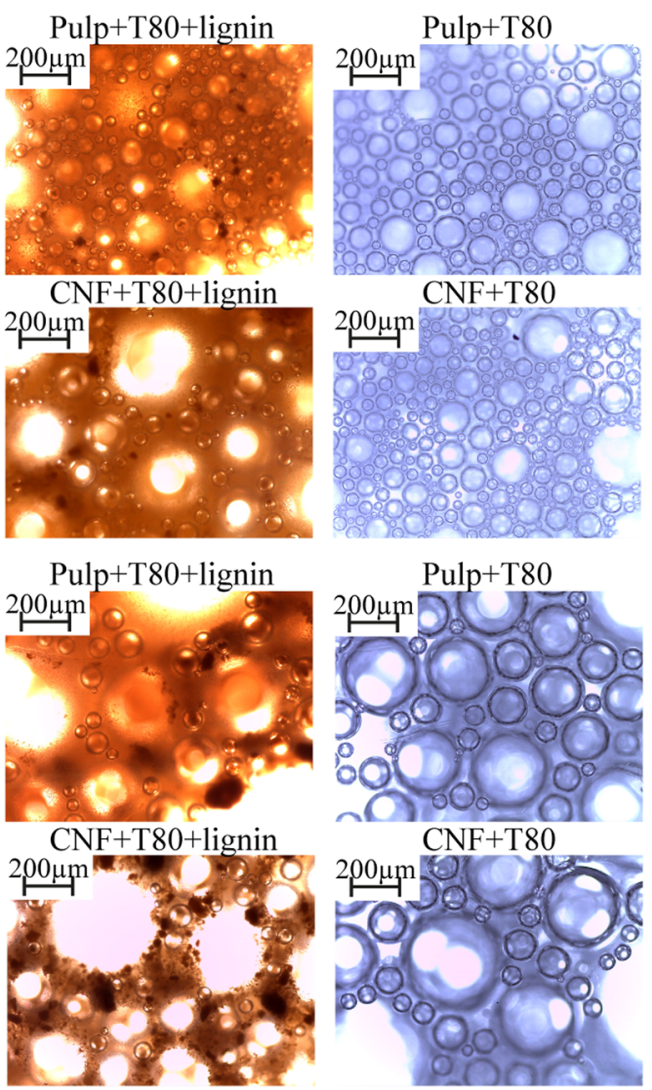

Pulp + T80+lignin

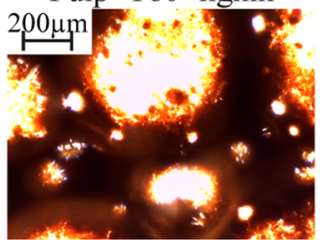

$\mathrm{CNF}+\mathrm{T} 80+$ lignin

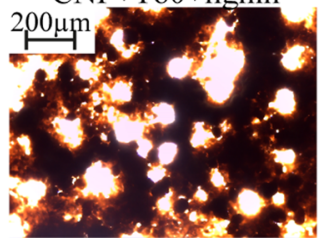

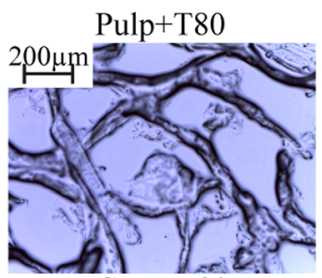

$\mathrm{CNF}+\mathrm{T} 80$

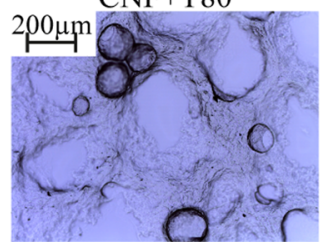

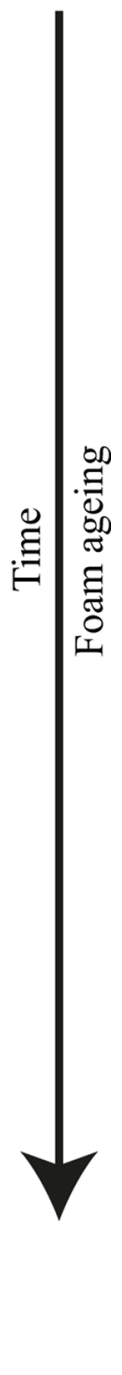

Fig. 5 Bubble size and shape: (a) immediately after foaming, (b) after $10 \mathrm{~min}$ and (c) after drying overnight at ambient conditions. A couple of milliliters of foam was deposited on a glass slide (Fig. S6) 
indicate that SDS foams were drier than T80 foams (Furuta et al. 2016).

All foams had polydisperse bubble sizes, which is known to negatively influence foam stability. The observed polydispersity is most likely due to the ageing process of foam since the bubbles had started to evolve and fuse into larger bubbles. The coalescence of foams is known to occur rapidly, and as there was a small time gap between foam generation and the first image of foam, it is rather difficult to say how monodisperse the foams have been originally (Langevin 2019). Monodispersed size distribution would slow down the coarsening since the migration of gas between the bubbles would be slower. After $10 \mathrm{~min}$ (Fig. 5b), the bubble size of all foams had increased compared to the starting point. The drainage of liquid from the foam phase due to gravity and capillary forces tends to cause the thinning of bubble films leading eventually to their rupture and coarsening of the foam. In T80 foams, the liquid occupied more space and it resembled more bubbly liquid than wet foam. The microscopy images of the foams support the conclusion based on drainage experiments that SDS foams were more stable than T80 foams. Although the bubble size of SDS foams increased with time, the structure did not change. After drying the foams overnight, the liquid had evaporated from foams and only solid material was seen on the glass plates (Fig. 5c). In all lignin-containing samples and CNF + SDS/T80, a honeycomb-like structure from bubbles could be seen, supporting our hypothesis that lignin and CNF acted as a supporting element for the foam structure as Pickering particles. Based on the observed honeycomb-like structure, the lignin particles and CNF seemed to be small enough to fit in the thin film between bubbles. The pulp fibers without lignin in Fig. 5c were randomly oriented, which implies that the fiber bundles were not trapped between foam bubble films, most likely due to their larger size. The diameter of CNF is in nanoscale, whereas pulp fibers are typically at the micron scale (Klemm et al. 2005, 2011). Additionally, hydrophilic pulp fibers are only physically trapped to the foam during the foaming and since there is no adhesion between fibers and bubbles, the location of fibers after draining is not clear (Ketola et al. 2020). Whereas with CNFs, it has been shown that due to their high aspect ratio and water-binding capacity they can effectively form a stable gel at the air-water interface of bubbles, form aggregates between bubbles and in this way hinder the drainage (Cervin et al. 2015; Xiang et al. 2019). This finding indicates that the stabilization of CNF and lignin-containing foams took place through two mechanisms; increase in viscosity (Murray and Ettelaie 2004; Xiang et al. 2019) and Pickering particle stabilization (Lam et al. 2014), whereas bleached pulp samples were stabilized only via a viscosity increase of the aqueous phase of the foam. The CNF-induced stabilization has been observed in similar SDS foam systems, in which most of the CNF was seen to remain in the foam phase, and the high water-holding capacity of CNF combined with formed CNF aggregates in plateau borders slowed down the liquid drainage and coalescence (Xiang et al. 2019).

\section{Thermal insulation}

Thermal insulation experiments were performed with pulp foams since variations in foam volumes between optimized CNF and pulp foams were small and from an application point of view, the pulp is a more economical raw material. Thermal insulation properties of the pulp foams (Table 1, tests 1 and 2) optimized for creating maximum foam volume with experimental design were assessed by acquiring thermal images with a FLIR ONE camera from foams on a hot plate (Fig. 6A).

Infrared temperature maps of optimized pulp foams indicated that the major difference in thermal insulation capability was due to the employed surfactant and its effect on foamability (Fig. 6b). The temperature of foams generated with T80 increased faster than SDS foams, and over time, the T80 foams exhibited an approximately $5{ }^{\circ} \mathrm{C}$ higher temperature compared to foams made with SDS, indicating that foams generated with T80 are poorer thermal insulators. The higher thermal conductivity of T80 foams was due to lower foamability in the applied experimental conditions (Fig. 2) and thus lower air content of the foam. The lower density of SDS stabilized foams (13-14 kg/ $\left.\mathrm{m}^{3}\right)$ compared to T80 stabilized foams $\left(25-45 \mathrm{~kg} / \mathrm{m}^{3}\right)$ also supports this finding. Moreover, SDS foams were more stable than T80 foams since, without support, the T80 foam collapsed on the hot plate, whereas the SDS foam dried to the shape of the spherical support ring (SI Fig. S7). While the addition of lignin increased the stability of the foams (Fig. 3a, b), lignin did not affect notably their thermal insulation properties (Fig. 6b). 


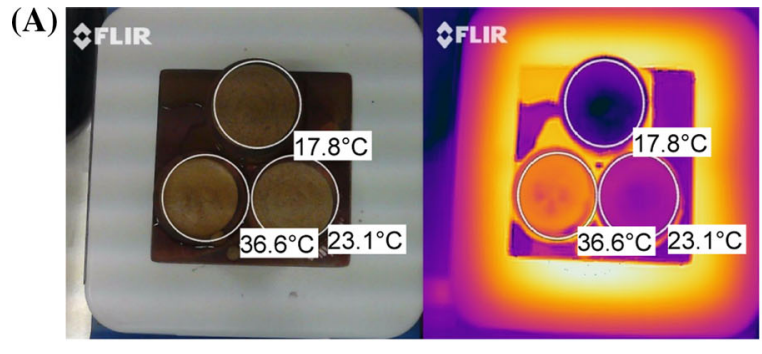

Fig. 6 a Optical (left) and thermal (right) images of foams with varying heights on a hot plate: $1 \mathrm{~cm}$ (bottom left), $2 \mathrm{~cm}$ (bottom right), and $4 \mathrm{~cm}$ (top) thick foams on a $51{ }^{\circ} \mathrm{C}$ hot plate. Images

However, some slight differences can be observed in the thermal insulation capability of pulp foams with and without lignin. In the first ten minutes of the experiment, the lignin containing foams showed higher temperature than neat foams. The lignin stabilized pulp foams had better stability after $5 \mathrm{~min}$ of foam generation (Fig. 3a) in terms of smaller drainage. In other words, they bound more water in the foam phase. Water has higher thermal conductivity than air, which could plausibly explain why the pulplignin foams with better stability showed lower thermal insulation capability. But on the other hand, the lignin containing pulp foam showed clear bubble structure even after drying (Fig. 5c), indicating that due to presence of lignin some of the bubble cell structure is preserved in dry state. The closed cells have a vital role for the thermal insulation capability of the dry foams as they hinder the convective heat transfer trough the material (Al-Homoud 2005).

The influence of pulp concentration and foam thickness on thermal insulation capability were investigated in separate tests. According to response surfaces the foams with the largest bleached pulp concentration of $12 \mathrm{~g} / \mathrm{L}$ were most stable in terms of the smallest drainage (Fig. 3 A, 4 A). In the thermal insulation experiments, the pulp concentration of $12 \mathrm{~g} / \mathrm{L}$ was not adequate to keep the foam stable as it collapsed in three hours (SI Fig. S8A). A pulp concentration of $18 \mathrm{~g} / \mathrm{L}$ seemed to be near the optimum since it provided stable foam and good thermal insulation, which was not further improved by additional pulp. Thermal insulation of the same foams with pulp concentrations of $18 \mathrm{~g} / \mathrm{L}$ and $27 \mathrm{~g} / \mathrm{L}$ were measured as wet and dry (SI Fig. S8B). It is evident that dry foams exhibited poorer thermal insulation

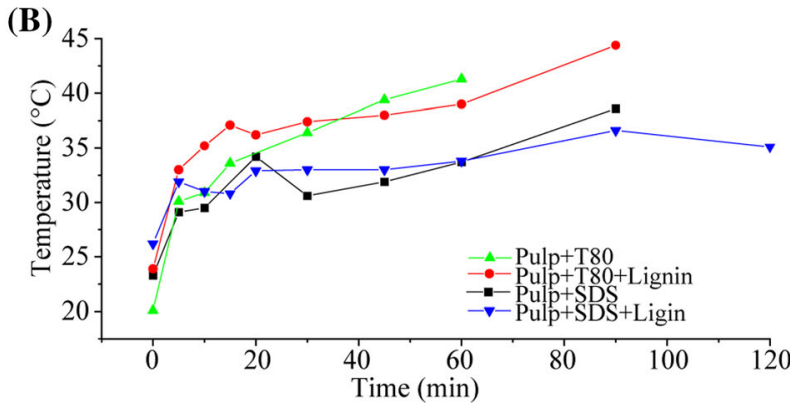

were taken immediately after foaming and transferring to the hot plate. b Temperature over time measured at the surface of $1 \mathrm{~cm}$ thick optimized pulp foams on a $54{ }^{\circ} \mathrm{C}$ hot plate

than wet foams due to reduced foam thickness. During the drying, the thicknesses of foams reduced because the structure collapsed due to drainage and the evaporation of liquid. The initial thickness was reduced even more for foam with higher pulp concentration during drying. Although the thermal insulation capability was somewhat lower in dry foams, the clear advantage of dry foams is their portability and mechanical strength. The effect of foam thickness on thermal insulation capability was studied with 1,2, and $4 \mathrm{~cm}$ thick wet foams (Fig. 7). All three thicknesses exhibited a drop in temperature in the beginning, which can be attributed to the drainage of excess liquid (SI Fig. S9). Based on temperature graphs it was obvious that the increase in foam thickness was the main factor improving the thermal insulation property of the foam. Even an increase of SDS concentration by 50\% did not improve the thermal insulation capability of foam (SI Fig. S9B).

The thermal conductivity of the two pulp foams of 2 and $4 \mathrm{~cm}$ thicknesses was compared to synthetic dry polystyrene (PS) foam of $2 \mathrm{~cm}$ thickness (Fig. 8a). It

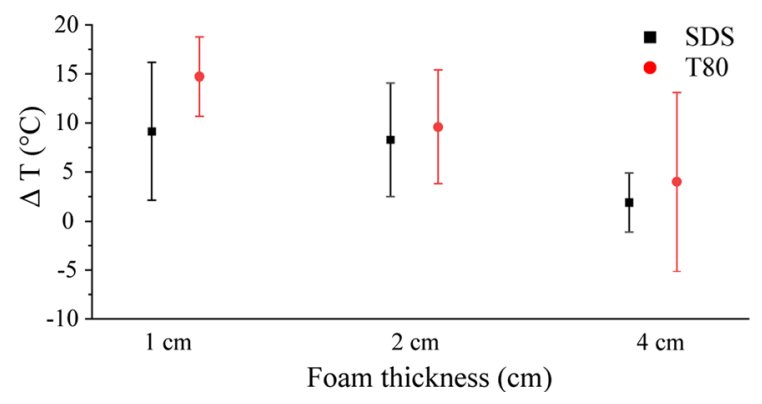

Fig. 7 The change in temperature over $3 \mathrm{~h}$ for 1,2 , and $4 \mathrm{~cm}$ thick wet pulp foams using SDS and T80 as surfactant 
(A)

\begin{tabular}{|l|l|l|}
\hline & \multicolumn{2}{|c|}{ W/mC } \\
\hline & $\mathbf{3 ~ h}$ & $\mathbf{2 4} \mathbf{~ h}$ \\
\hline Pulp 2 cm & $0.039-0.050$ & $0.047-0.061$ \\
\hline Pulp 4 cm & $0.018-0.024$ & $0.038-0.050$ \\
\hline PS 2 cm & \multicolumn{2}{|c|}{$0.031-0.04$} \\
\hline
\end{tabular}

(B)

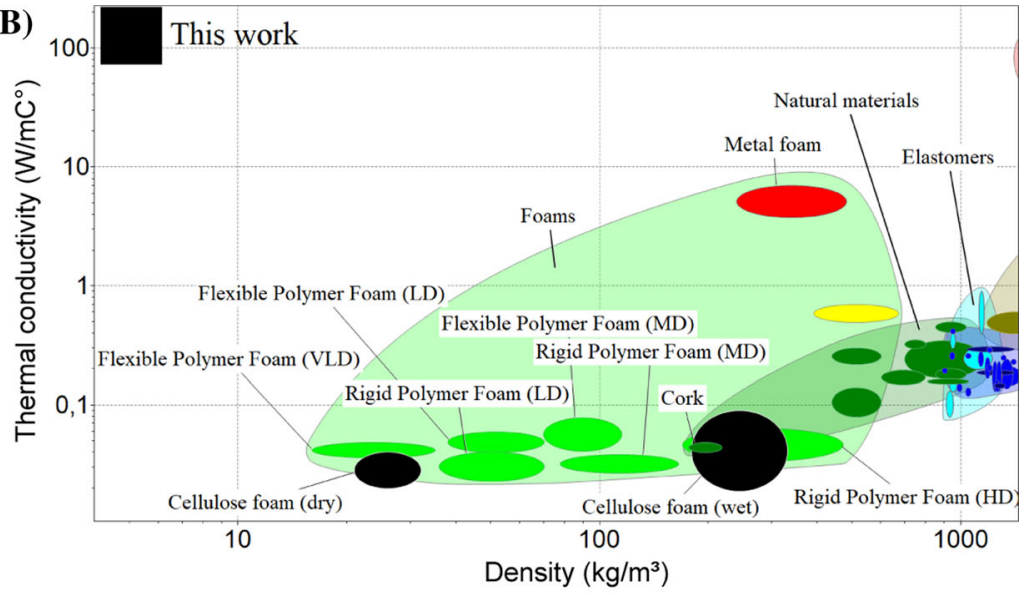

(C)

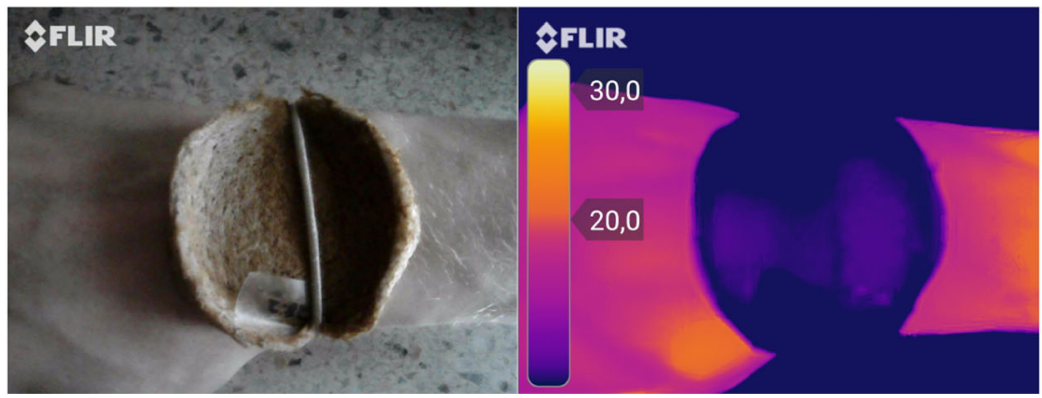

Fig. 8 a Thermal conductivity $(W)$ of pulp and dry polystyrene (PS) foams over time, b Ashby diagram/ material properties of wet and dry cellulose foam compared to other natural materials and conventional foam materials (Granta Edupack 2019),

showed that after $2 \mathrm{~h}$ of application, the thicker foam was a more efficient thermal insulator than PS foam and after $24 \mathrm{~h}$ the thermal conductivity of the thicker dried pulp foam was within the same order of magnitude as the PS foam. The variance in thermal conductivity overtime was smaller for PS foam than for pulp foam because PS foam was initially dry and thus maintained the same structure.

Both dry and wet pulp foams exhibited an excellent combination of low thermal conductivity and density compared to various polymeric foams and natural materials (Fig. 8b). Even though the thickness decreased and thermal conductivity increased during drying, also the dry foam could be applicable as a thermal camouflage material, as shown in Fig. 8c. This indicates that the foams presented here are not only applicable as wet foams providing temporary stealth, but also as dry stealth foams after removing water. Lignin containing SDS-stabilized pulp foam was selected as a proof-of-concept material since c Proof-of-concept thermal camouflage foam of $2 \mathrm{~cm}$ thickness on a human arm with granite background at room temperature. The temperature of the foam-covered part matches the background

SDS-based foam was found to have the best foaming and thermal properties, and lignin improved the structural stability of the foam. The results suggested that in the very first minutes the better stability of foam impaired the thermal insulation properties of the foam. The high concentration of pulp, CNF, and lignin improved the stability of foam in terms of drainage, meaning the water was more efficiently maintained in the foam phase compared to foams with lower pulp/ $\mathrm{CNF}$ and lignin concentration. The more stable foams with more water in their foam phase had adverse effect on the thermal conductivity since water is thermally more conducting than air. However, lignin was found significant for the long-term stability of foam and the dry foam containing both pulp and lignin showed sufficient insulation properties. For stealth applications, the brown color of lignin is also advantageous, decreasing the spectral visibility in a forest environment compared to the purely white foam obtained using only bleached pulp fibers without lignin. This 
proof-of-concept material showed good coverage of a human arm's thermal signal as the temperature of the foam-covered part of the arm matched the background material. The advantage of these lightweight, natural stealth foams compared to the actively studied infrared thermal metamaterials is the scalability. Many of these interesting stealth materials are feasible to produce only on a centimeter scale, which is not enough to camouflage vehicles, for instance (Hu et al. 2018; Zhang et al. 2015). In contrast, pulp and lignin are available in large quantities and at a low price. SDS is also one of the most used surfactants. Except the very small amount of surfactant, all the other ingredients originate from the forest and are both biobased and decompose more easily than their synthetic counterparts. The production of these bio-based stealth materials is hence both scalable and sustainable.

\section{Conclusions}

In this work, a thermal camouflage foam was produced using low-cost surfactants and renewable materials only. Experimental design and response surface methodology were used to find the optimum concentration ranges for surfactants, fibers or fibrils, and lignin, which created the maximum amount of foam with the best stability. SDS was a more efficient foaming agent than T80 under the conditions tested. Both pulp fibers and CNF were able to stabilize the foams by decreasing the drainage; the CNF was more efficient after $5 \mathrm{~min}$, but the difference diminished after a longer time period. Based on its lower price and better availability, the bleached pulp was selected for thermal camouflage testing. Bleached pulp foams with SDS in the wet and dry state showed excellent thermal properties, comparable to dry polystyrene foam. Lignin was found to provide structural support to the foam but it did not influence the foamability or thermal conductivity of the foams. A proof-of-concept material was proven to successfully thermally camouflage body temperature to match the temperature of the background at room temperature. The results show that these lignocellulosic foams can be a renewable and natural option for thermal insulation applications. Besides thermal camouflage, the foams could potentially provide visual stealth in a forest environment and other terrains owing to the brown coloration created with lignin. In addition to mechanical stirring, other foaming methods could be applied, such as gas foaming, to achieve more feasible large-scale foam generation.

Acknowledgments The authors thank Marja Kärkkäinen for providing the bleached pulp and Tuyen Nguyen for providing cellulose nanofibrils. We are grateful for the support by the FinnCERES Materials Bioeconomy Ecosystem and this work made use of Aalto University Bioeconomy Facilities.

Funding Open Access funding provided by Aalto University. This work was funded by The Scientific Advisory Board for Defence (MATINE, 2500 M-0110).

Data availability Supplementary material.

Code availability Not applicable.

\section{Declarations}

Conflict of interest The authors declare that they have no conflict of interest.

Open Access This article is licensed under a Creative Commons Attribution 4.0 International License, which permits use, sharing, adaptation, distribution and reproduction in any medium or format, as long as you give appropriate credit to the original author(s) and the source, provide a link to the Creative Commons licence, and indicate if changes were made. The images or other third party material in this article are included in the article's Creative Commons licence, unless indicated otherwise in a credit line to the material. If material is not included in the article's Creative Commons licence and your intended use is not permitted by statutory regulation or exceeds the permitted use, you will need to obtain permission directly from the copyright holder. To view a copy of this licence, visit http://creativecommons.org/licenses/by/4.0/.

\section{References}

Ago M, Ferrer A, Rojas OJ (2016) Starch-based biofoams reinforced with lignocellulose nanofibrils from residual palm empty fruit bunches: water sorption and mechanical strength. ACS Sustain Chem Eng 4:5546-5552. https://doi. org/10.1021/acssuschemeng.6b01279

Al-Homoud MS (2005) Performance characteristics and practical applications of common building thermal insulation materials. Build Environ 40:353-366. https://doi.org/10. 1016/j.buildenv.2004.05.013

Alwadani N, Fatehi P (2018) Synthetic and lignin-based surfactants: challenges and opportunities. Carbon Resour Convers 1:126-138. https://doi.org/10.1016/j.crcon.2018. 07.006

Amaral MH, das Neves J, Oliveira ÂZ, Bahia MF (2008) Foamability of detergent solutions prepared with different 
types of surfactants and waters. J Surfactants Deterg 11:275-278. https://doi.org/10.1007/s11743-008-1088-0

Arevalo-Gallegos A, Ahmad Z, Asgher M et al (2017) Lignocellulose: a sustainable material to produce value-added products with a zero waste approach-a review. Int J Biol Macromol 99:308-318. https://doi.org/10.1016/j.ijbiomac. 2017.02.097

Bikerman JJ (1938) The unit of foaminess. Trans Faraday Soc 34:634-638. https://doi.org/10.1039/TF9383400634

Casero I, Sicilia D, Rubio S, Pérez-Bendito D (1997) Study of the formation of dye-induced premicellar aggregates and its application to the determination of quaternary ammonium surfactants. Talanta 45:167-180. https://doi.org/10. 1016/S0039-9140(97)00117-3

Cervin NT, Johansson E, Benjamins J-W, Wågberg L (2015) Mechanisms behind the stabilizing action of cellulose nanofibrils in wet-stable cellulose foams. Biomacromol 16:822-831. https://doi.org/10.1021/bm5017173

Chou DK, Krishnamurthy R, Randolph TW et al (2005) Effects of tween $20 \AA$ and tween $80 \AA$ on the stability of albutropin during agitation. J Pharm Sci 94:1368-1381. https://doi. org/10.1002/JPS.20365

Deepti Yadav MK, Arora KC, Tiwari JKG (2018) Detection and identification of camouflaged targets using hyperspectral and LiDAR data. Def Sci J. 68:540-546. https://doi.org/10. 14429/dsj.68.12731

Drenckhan W, Hutzler S (2015) Structure and energy of liquid foams. Adv Colloid Interface Sci 224:1-16. https://doi.org/ 10.1016/j.cis.2015.05.004

Drenckhan W, Saint-Jalmes A (2015) The science of foaming. Adv Colloid Interface Sci 222:228-259. https://doi.org/10. 1016/j.cis.2015.04.001

European Commission (2018) A Clean Planet for all. A European long-term strategic vision for a prosperous, modern, competitive and climate neutral economy. Com 773

Farooq M, Sipponen MH, Seppälä A, Österberg M (2018a) Ecofriendly flame-retardant cellulose nanofibril aerogels by incorporating sodium bicarbonate. ACS Appl Mater Interfaces 10:27407-27415. https://doi.org/10.1021/ ACSAMI.8B04376

Farooq M, Zou T, Riviere G et al (2018b) Strong, ductile, and waterproof cellulose nanofibril composite films with colloidal lignin particles. Biomacromol 20:693-704. https:// doi.org/10.1021/ACS.BIOMAC.8B01364

Ferreira ES, Cranstion ED, Rezende CA (2020) Naturally hydrophobic foams from lignocellulosic fibers prepared by oven-drying. ACS Sustain Chem Eng 8:8267-8278. https://doi.org/10.1021/acssuschemeng.0c01480

Furuta Y, Oikawa N, Kurita R (2016) Close relationship between a dry-wet transition and a bubble rearrangement in two-dimensional foam. Sci Rep 6:1-8. https://doi.org/10. 1038/srep37506

Granta Edupack software 2019, Granta Design Limited, Cambridge, UK.

Hu R, Zhou S, Li Y et al (2018) Illusion thermotics. Adv Mater 30:1707237. https://doi.org/10.1002/ADMA.201707237

Jiménez-Saelices C, Seantier B, Cathala B, Grohens Y (2017) Spray freeze-dried nanofibrillated cellulose aerogels with thermal superinsulating properties. Carbohydr Polym 157:105-113. https://doi.org/10.1016/j.carbpol.2016.09. 068
Ketola AE, Xiang W, Hjelt T et al (2020) Bubble attachment to cellulose and silica surfaces of varied surface energies: wetting transition and implications in foam forming. Langmuir 35:7296-7308. https://doi.org/10.1021/acs. langmuir.0c00682

Kim J, Han K, Hahn JW (2017) Selective dual-band metamaterial perfect absorber for infrared stealth technology. Sci Rep 7:1-9. https://doi.org/10.1038/s41598-017-06749-0

Klemm D, Heublein B, Fink HP, Bohn A (2005) Cellulose: fascinating biopolymer and sustainable raw material. Angew Chemie Int Ed 44:3358-3393. https://doi.org/10. 1002/anie.200460587

Klemm D, Kramer F, Moritz S et al (2011) Nanocelluloses: a new family of nature-based materials. Angew Chemie Int Ed 50:5438-5466. https://doi.org/10.1002/anie.201001273

Lam S, Velikov KP, Velev OD (2014) Pickering stabilization of foams and emulsions with particles of biological origin. Curr Opin Colloid Interface Sci 19:490-500. https://doi. org/10.1016/J.COCIS.2014.07.003

Langevin D (2017) Aqueous foams and foam films stabilised by surfactants. Gravity-Free Studies Comptes Rendus Mec 345:47-55. https://doi.org/10.1016/j.crme.2016.10.009

Langevin D (2019) Coalescence in foams and emulsions: similarities and differences. Curr Opin Colloid Interface Sci 44:23-31. https://doi.org/10.1016/J.COCIS.2019.09.001

Lappalainen T, Lehmonen J (2012) Determinations of bubble size distribution of foam-fibre mixture using circular hough transform. Nord Pulp Pap Res J 27:930-939. https://doi. org/10.3183/NPPRJ-2012-27-05-p930-939

Li S, Willoughby JA, Rojas OJ (2016a) Oil-in-Water emulsions stabilized by carboxymethylated lignins: properties and energy prospects. Chemsuschem 9:2460-2469. https://doi. org/10.1002/cssc. 201600704

Li S, Xiang W, Järvinen M et al (2016b) Interfacial stabilization of fiber-laden foams with carboxymethylated lignin toward strong nonwoven networks. ACS Appl Mater Interfaces 8:19827-19835. https://doi.org/10.1021/acsami.6b06418

Mäkelä M (2017) Experimental design and response surface methodology in energy applications: a tutorial review. Energy Convers Manag 151:630-640. https://doi.org/10. 1016/j.enconman.2017.09.021

Mendoza L, Batchelor W, Tabor RF, Garnier G (2018) Gelation mechanism of cellulose nanofibre gels: a colloids and interfacial perspective. J Colloid Interface Sci 509:39-46. https://doi.org/10.1016/j.jcis.2017.08.101

Murray BS (2020) Recent developments in food foams. Curr Opin Colloid Interface Sci 50:101394. https://doi.org/10. 1016/j.cocis.2020.101394

Murray BS, Ettelaie R (2004) Foam stability: proteins and nanoparticles. Curr Opin Colloid Interface Sci 9:314-320. https://doi.org/10.1016/j.cocis.2004.09.004

Nechita P, Nâstac S (2017) Foam-formed cellulose composite materials with potential applications in sound insulation. J Compos Mater 52:747-754. https://doi.org/10.1177/ 0021998317714639

Nemoto J, Saito T, Isogai A (2015) Simple freeze-drying procedure for producing nanocellulose aerogel-containing, high-performance air filters. ACS Appl Mater Interfaces. 7:19809-19815. https://doi.org/10.1021/acsami.5b05841

Paria S, Manohar C, Khilar KC (2005) Adsorption of anionic and non-ionic surfactants on a cellulosic surface. Colloids 
Surf a: Physicochem Eng Asp 252:221-229. https://doi. org/10.1016/j.colsurfa.2004.09.022

Petkova R, Tcholakova S, Denkov ND (2012) Foaming and foam stability for mixed polymer-surfactant solutions: effects of surfactant type and polymer charge. Langmuir 28:4996-5009. https://doi.org/10.1021/la3003096

Rio E, Drenckhan W, Salonen A, Langevin D (2014) Unusually stable liquid foams. Adv Colloid Interface Sci 205:74-86. https://doi.org/10.1016/j.cis.2013.10.023

Saint-Jalmes A (2006) Physical chemistry in foam drainage and coarsening. Soft Matter 2:836-849. https://doi.org/10. 1039/b606780h

Sakai K, Kobayashi Y, Saito T, Isogai A (2016) Partitioned airs at microscale and nanoscale: thermal diffusivity in ultrahigh porosity solids of nanocellulose. Sci Rep 6:1-7. https://doi.org/10.1038/srep20434

Samaras K, Kostoglou M, Karapantsios TD, Mavros P (2014) Effect of adding glycerol and Tween 80 on gas holdup and bubble size distribution in an aerated stirred tank. Colloids Surfaces A Physicochem Eng Asp 441:815-824. https:// doi.org/10.1016/j.colsurfa.2013.02.031

Stevenson P (2012) Foam engineering: fundamentals and applications. John Wiley \& Sons Ltd, United Kingdom. https://doi.org/10.1002/9781119954620

United Nations (2015) Transforming Our World: the 2030 Agenda for Sustainable Development A/RES/70/1. https:// www.un.org/ga/search/view_doc.asp?symbol=A/RES/70/ $1 \&$ Lang $=\mathrm{E}$

Wang Z, Cheng Y, Nie Y et al (2014) Design and realization of one-dimensional double hetero-structure photonic crystals for infrared-radar stealth-compatible materials applications. J Appl Phys 116:54905. https://doi.org/10. 1063/1.4892088

Wang J, Nguyen AV, Farrokhpay S (2016) A critical review of the growth, drainage and collapse of foams. Adv Colloid Interface Sci 228:55-70. https://doi.org/10.1016/j.cis. 2015.11.009

Wu C, Nesset K, Masliyah J, Xu Z (2012) Generation and characterization of submicron size bubbles. Adv Colloid Interface Sci 179-182:123-132. https://doi.org/10.1016/j. cis.2012.06.012

Xiang W, Preisig N, Ketola A et al (2019) How cellulose nanofibrils affect bulk, surface, and foam properties of anionic surfactant solutions. Biomacromol 20:4361-4369. https://doi.org/10.1021/acs.biomac.9b01037

Xu Q, Nakajima M, Ichikawa S et al (2009) Effects of surfactant and electrolyte concentrations on bubble formation and stabilization. J Colloid Interface Sci 332:208-214. https:// doi.org/10.1016/J.JCIS.2008.12.044

Zhang Y, Xu H, Zhang B (2015) Design, implementation, and extension of thermal invisibility cloaks. AIP Adv. https:// doi.org/10.1063/1.4913996

Zhao Y, Brown MB, Jones SA (2010) Pharmaceutical foams: are they the answer to the dilemma of topical nanoparticles? Nanomed Nanotechnol, Biol Med 6:227-236. https:// doi.org/10.1016/j.nano.2009.08.002

Publisher's Note Springer Nature remains neutral with regard to jurisdictional claims in published maps and institutional affiliations. 